\title{
Impact of Out-of-School Time Technology Integration Modelling on Mathematics Performance: A Case of Primary Schools in Meru District, Tanzania
}

\author{
Thadei A. Kiwango, PhD \\ ORCID: 0000-0002-7016-9165 \\ Department of Informatics \\ Institute of Accountancy Arusha \\ Corresponding Mail: tkiwango@gmail.com
}

\begin{abstract}
Copyright resides with the author(s) in terms of the Creative Commons Attribution CC BY-NC 4.0. The users may copy, distribute, transmit and adapt the work, but must recognize the author(s) and the East African Journal of Education and Social Sciences
\end{abstract}

\begin{abstract}
This study sought to establish the impact of modelling technology integration for of Out-ofSchool Time (OST) learning on the performance in Mathematics in primary schools. The study adopted a mixed approach where both quantitative and qualitative data were analysed. The study employed an experimental design involving the experimental and the control groups. Each of the two groups comprised three (3) schools, making a total of six out of 152 primary schools in Meru District. The findings reveal a statistically significant difference in mean scores between the control and the experimental group. The study concluded that modelling of technology integration for OST learning is attributed to significant improvements in performance of Mathematics in primary schools. Apart from building pupils' interest, confidence and creativity in mathematics, technology integration modelling enticed teachers, parents and pupils to collaboratively dedicate more time and commitment in favour of the mathematics subject. The study recommends that school administrators and teachers need to cooperate with parents to encourage and support primary school children to embrace positive use of educational technology particularly in OST learning.
\end{abstract}

Keywords: Technology integration modelling, out-of-school time, Mathematics performance, primary schools

How to cite: Kiwango, T. A. (2021). Impact of Out-of-School Time Technology Integration Modelling on Mathematics Performance: A Case of Primary Schools in Meru. East African Journal of Education and Social Sciences 2(4), 75-88. Doi: https://doi.org/10.46606/eajess2021v02i04.0130

\section{Introduction}

Learning is a life-long process in that it can happen at any place and time. This is particularly so in the present era of technology where the teaching and learning process is mediated by educational technology (Hultman, 2004). However, adoption of any technology, especially educational technology, is determined by the extent to which potential adopters are informed of the availability and usefulness of relevant technologies. In the case of Out of School Time Learning, learners can be effectively informed and influenced to adopt relevant technologies through establishment of specific guidelines and models.

It is reported that participation of learners in using OST learning technology correlates positively with enhanced school attendance, interpersonal skills and aspirations for higher learning (Schinke, 1999; U.S Department of Education, 1998; Posner \& Vandell, 1999). Participation of learners is also linked with reduced drop-out and early pregnancy rates, improved academic performance and avoidance of risky practices and behaviors (Huang et al., 2000; McLaughlin, 2000; Clark, 1988; Hamilton 
and Klein, 1998; Metlife Foundation, 2011). Therefore, it is the assumption of this study that school and out-of-school time learning can be integrated for improving academic performance in general and mathematics performance in particular.

According to Rob (1996), determining educational performance should consider various aspects like quality of education, access as well as equity. Centre for Public Education (2016) indicates that equity in education can be realized by ensuring that learners have access to necessary resources without regard to social class, gender or physical and mental abilities. In the view of Rob, access to important supplies may depend on different factors including proximity to facilities, socio-cultural backgrounds and direct costs. Quality of education is viewed in terms of skills and knowledge that potentially reflect the level of education (Sigalla, 2013). For example, with reference to reading and writing among Class One pupils, quality education can be determined in relation to ability to read and write.

It is reported that about $50 \%$ of Tanzanian primary school pupils in 2004 and 2013 performed poorly in the Primary School Leaving Examination (PSLE) where performance in Mathematics was the worst (Mazana et al., 2020; Njiku, 2019; Sumra \& Katabaro, 2014). The International Institute for Educational Planning (IIEP) (2010) adds that less than $10 \%$ of pupils in Tanzania could solve multipleoperation problems involving fractions, ratios and decimals while only $2.5 \%$ of them could solve multistep problems. A study conducted by Kalhotra (2013) in India discovered that causes of mass failure in Mathematics include lack of supervisory support at home. Malmberg and Sumra (2001) revealed that home environment is among the key factors for quality education in Tanzania. This justifies the need to develop a model that directs teachers and parents to encourage and guide school children to make effective use of the OST for academic pursuits.

There are varied approaches to motivating school children to exploit the OST learning technology. However, the approaches differ across cultures and contexts. For example, although the United States of America is among the pioneers of community-based OST programs, the efficiency of programs is affected by financial obligations and geographical diversity between schools, homes and the program centers (miller, 1995). In many parts of the developing world, children who have been placed in private tuitions of various kinds have produced negative outcomes (Mark, 2003). As a result, private tuition practice in Tanzania was officially prohibited by the Ministry of Education and Culture in 1998, although it did not completely fade away (Amon et al., 2003; (URT), 1998).

In what seems to be an attempt to address the negative effect of unsystematic out of school environment, OST learning technology has burst to the scene. In Africa, for instance, the Nokia Mobile Mathematics (Momaths) project has delved into OST technology with a focus on the teaching and learning of mathematics using mobile devices (UNESCO, 2014). As for Tanzania, the Tanzanian Commission for Science and Technology (COSTECH) initiated the Momaths project in 2014 (Ipp media October 19, 2014). Similar efforts have been made by ELIMU Community Light (ECOLI) whereby mobile technology is used to guide, remind and inform teachers, parents and families about skills and best approaches to mediating learning out of the school environment (Center for Education Innovations, n.d).

In Tanzania, some projects have joined the efforts towards OST learning initiatives. These include the Ubongo Kids project (Communication Initiative Network, 2014) which is particularly intended to mediate the learning of mathematics and science in primary schools through songs, funs and local stories. Given the success of the Ubongo Kids programme, more programmes are needed to cater for the ever-expanding needs. Studies around the world show that school children have not efficiently exploited educational technologies (Adomi and Kpangban, 2010; Swart and Wachira 2010). With respect to this, the Chalk Board Project (2008) and Terzian, et al. (2009) support that availability of educational technology is not by itself enough to improve academic performance if not associated with models that motivate its adoption.

Most studies have focused on teaching and learning models which are primarily classroom-based, thereby leaving a lot to be desired in terms of OST learning (Georgia et al., 2004). This paper is an attempt to assess the situation in the Tanzania context, drawing experiences from Kiwango's (2018) model. The model defines strategies that motivate teachers, parents and learners to collectively participate in utilization of educational technology in OST learning for better academic performance of 
primary school children. The study was guided by the following research questions:

1. Does Technology integration modelling for out-of-School Time Learning improve performance in Mathematics in Primary Schools?

2. What are the perceptions of primary school teachers, parents and learners on the usefulness of technology integration modelling in improving the environments for teaching and learning of mathematics in OST?

\section{Literature Review}

\section{The Concept of Out-of-School Time Learning}

Learning in the context of OST comprises a wide scope of instructional practices that take place out of school premises and routines (Indianapolis Afterschool Coalition, 2002). The practices could be conducted before school, after school as well as on weekends and holidays. This is contrary to the traditional practices which constrain learning to classrooms. The merits of OST include the ability of learners to win the support of the family, and maximized interactions with the digital media (Sarah et al., 2012).

One way through which OST learning can be made effective is participation of learners (Clark, 1998; Hamilton and Klein, 1998). Accordingly, learners' participation has been found to improve school attendance and develop more positive attitudes towards learning. Moreover, pupils cultivate higher aspirations for college and reduce drop-out while developing better interpersonal skills. Huang et al. (2000) and McLaughlin (2000) add that with OST programs, pupils are left with limited time to spend in risky behaviors, thereby improving academic performance and reducing early pregnancy cases.

\section{Theoretical Underpinnings \\ Theory of Constructivism}

The Theory of Constructivism assumes that learners construct meaning by actively participating to develop cognitive representations of what they learn (Juniu, 2006; Jonassen, Peck, \& Wilson, 1999). Constructivists have the view that OST learning sufficiently supplements children's school experiences (Maddux, 2001). In the views of Juniu (2006), constructivist thinking in teaching and learning can be mediated by technology to make learners self-motivated and committed to critical thinking. The term techno-constructivist entails instructional practices that integrate technology into the school curriculum in a manner that it complements and refines teaching and learning processes (McKenzie, 2000). This is in line with Rakes, et al. (1999) who argue that "technology provides the vehicle for accomplishing constructivist teaching practices." Constructivist methods are positively correlated with the nature and extent of the available technology and the technological skills that instructors possess and use. According to Collins (1991), technology-rich contexts enhance learner's autonomy and allow individualized and active learning. The adopted theory is relevant to this study as it underscores the significance of technology integration in the instructional settings.

\section{Harvard Family Research Project (HFRP) Logic model for OST}

As articulated by Kellogg Foundation (2000), a logic model describes a programme with respect to activities, available resources and the expected end results. According to Watson (2000), a logic model comprises six components: expected outcomes; motivating conditions and causes; strategies; activities; outcome performance and performance indicators. It has been claimed further that logic models are recognized as powerful tools for designing, planning, implementing and evaluating the outcomes of OST learning technology (Hamilton, 2007). HFRP (1999) characterizes the logic model in relation to four components: inputs, activities, outputs and outcomes and customize the same for use in OST programmes. On the one hand, inputs are essentially plans and resources adopted in the evolution of the programme. On the other hand, activities relate to definition of the main tasks and activities to be undertaken when implementing the envisaged programme. Moreover, some aspects of the programme may change instantly depending on the programme implementation. Finally, outcomes pertain to changes in the performance as measured on the individual or the community at large. This paper subscribes to the HFRP model owing to its insistence on the significance of evaluating the outcomes of OST learning. Although the HFRP logic model addresses the OST situations, its origin lacks a focus on technology integration in primary schools, particularly in Tanzanian contexts.

\section{Out-of-school time learning technology integration model}

Kiwango (2018) designed a model consisting of three main constructs: the OST technology integration strategies, hastened integration of 
technology and improved academic performance to inform the integration of OST technology. The construct OST technology integration strategies involve seven strategies which are: stakeholders' perceptions assessment, stakeholders' perceptions validation, partnership contracting, capacity building, acquisition of technology, deployment of technology and participant evaluation. Strategies adopted are intended to hasten technology integration and are implemented in a linear fashion, staring with the assessment of stakeholders' perceptions and completing with participant evaluation. While the first two strategies were implemented before the experiment the fourth strategy was incorporated to the model further to the experiment. Thus, these three strategies were not part and parcel of the experiment on board. On the other hand, the construct Hastened technology integration is measured in terms of actual technology use, intensity of technology use, timeliness of technology use and initiative for technology use. This study majors on evaluating the impact of the strategies stipulated by the model on the academic performance in mathematics.

\section{Research Methodology}

Research design

This study employed an experiment design which comprised of the experimental and the control groups. Quantitative data was complemented by qualitative data generated from perceptions of key stakeholders, namely teachers, parents and learners in relation to the applicability of the proposed model in enhancing pupils' performance in mathematics. The experiment was carried out in selected primary schools in Meru District, Tanzania. The location was conveniently selected owing to sufficient access to technological digital devices among its population (Lamudi, 2015; TCRA, 2013). As the area was also peri-urban, it was envisaged that the population would be informed of educational technology, accommodating sociocultural and economic characteristics of most Tanzanians, as opposed to purely urban or rural populations (Kelly, 2013).

The study involved a quasi-experiment that intended to determine the influence of technology integration modelling on pupils' performance in Mathematics. Quasi-experiment is an experiment that is conducted in natural environments like schools and does not allow full control and random assignment of respondents (Creswell, 2005).

\section{Population and Sampling}

The experiement involved 6 out of 152 primary schools in Meru District. Criterio sampling was used to select these schools by considering certain conditions. Firstly, the experiement intended to involve day schools because it was set to daily OST learning activities and so boarding schools could not be suitable. Secondly; Schools were to be selected from the location that extends within four kilometers along the Moshi-Arusha highway so as to ease the movements of researchers and teachers which was necessary for the experiment. Thirdly, the researcher intended to select schools whose target class had at least 30 pupils with television at home so as to make the experiment practical. In this case, 12-day schools were found to meet these conditions.

Moreover, the researcher intended to trade-off the differences in supervisory supports offered to pupils at home, that could affect the experiment. Hence, through a questionnaire, pupils in these schools were requested to rate the supervision they were offered. The rates of supervisory service were quantified and averaged for each school. These schools were then sorted into 3 batches on the basis of the indicated supervisory supports as higher, moderate and low, where each batch comprised of 4 schools. Then, 2 schools were selected from the mid of each batch where 1 school was assigned to experimental and another one to control group summing to 6 schools. The study involved class six pupils in both groups that had television set at home which summed to 167 and 143 for experimental and control group respectively. Class six pupils were not busy with National examinations as class seven and therefore were considered matured enough to participate in the experiment. Since the model demanded the participation of teachers and parents, the experimental group involved 127 parents, 5 mathematics teachers and 3 head teachers who volunteered to participate.

\section{Treatment of Experimental and Control Groups}

The use of the educational technology for the experimental group was guided under the strategies pertaining to the model while their counterparts were treated under the traditional practices. It is on the basis of this difference that the effectiveness of the new model was measured. Both groups were exposed to the experiment for a consecutive period of three (3) months. 


\section{Research Instruments}

Data collection involved a wide range of instruments to reach the involved pupils, parents and teachers as explained below:

\section{Digital Video Disks}

Digital Video Discs (DVDs) with class six learning content were availed to pupils in both experimental and control groups. The aim was to make the pupils view the content using appropriate technology at home. The DVDs gave the OST learners the opportunity to use different digital devices, including desktop computers, laptops and televisions. DVDs were thought to be ideal given their affordability, accessibility, ease of use and compatibility. The DVD sets included the main DVD which contained the contents of mathematics topics that were to be taught in class six during the experiment. The other DVD covered the contents of class six mathematics topics that were taught prior to the experiment. The content in the DVDs was based on the National Examination Council of Tanzania curriculum and thus, all class six topics were covered. Topics were divided into sub topics and each ran for approximately 15 minutes. Moreover, the materials for each sub topic were specified in the home assignment booklets. Under the supervision and assistance of parents and/or other adults, learners had to prepare in advance. Before the actual practice, teachers oriented their pupils to the technology application. During the presentation, pupils could select a topic, pause, rewind, forward and replay the content conveniently.

\section{Home Assignment Booklets}

Along with DVDs, home assignments were also made available to pupils to reinforce the use of the educational technology. The booklets were designed in relation to the supplied DVDs such that one set of booklets related to the main DVD and the other related to the revision DVD. The booklets for the main DVD were given at the beginning of the experiment and comprised four topics which had not yet been covered in classroom whereas the revision booklets were given before the experiment, comprising six topics which had already been covered before the experiment. The revision booklets were supplied after pupils had attempted all activities in the main DVD. In short, the questions demanded the pupils to be able to follow and understand the main concepts taught through the DVD. The pupils then answered questions and produced answers in the provided answer sheets.
Then, the answer sheets were collected to mathematics teachers, ready for subsequent marking. The role of head teachers was mainly to ensure that mathematics teachers collected the answer sheets from pupils on daily basis.

A panel of two Mathematics teachers was hired from a different primary school to do the marking. The hired markers were not informed of the experiment, and they were the same who set both the questions and marking schemes. Two independent experts reviewed and refined the home assignment booklets, marking schemes and the marked papers. Before developing the final version of the test instruments, the comments of the reviewers were communicated to the examination setters for scrutiny and adoption. The DVDs were availed to the examination setters and reviewers to familiarize with the content.

\section{Test papers}

To determine the effectiveness of the developed OST learning technology, a pilot test, pre-test and three monthly tests were administered to the involved pupils. It was important for the researcher to consult the lesson plans for the involved schools in order to determine the teaching schedules and subject coverage. This was necessary in the preparation of a tentative examination calendar. The calendar was then shared with respective mathematics teachers, head teachers and pupils so that they could prepare for the intended tests. The test items contained the topics which had been covered a week prior to the test date. The test items were set on the basis of the NECTA curriculum. For instance, pupils were required to demonstrate the ability to understand the concepts, and apply the same in solving daily problems.

The examination begun with a pilot test in order to enable the researcher to be acquainted with respective environments and do necessary adjustments. The test papers reached the schools at least 30 minutes before the commencement of the test to give examiners sufficient time to address any issues that might arise. It was also important to set a communication point for handling pertinent issues, and this was solely the responsibility of the researcher. The researcher was also responsible for ensuring the readiness of all schools to commence the examination and communicate with all schools. After marking the pilot test, the papers were taken back to the pupils. The pilot test was solely intended for assessing the field environments and hence the marks were not used in the stage of data analysis. 
Then, the first test (technically termed as pre-test according to Analysis of covariance - ANCOVA) was given seven days later, followed by other three tests on monthly basis. The test papers were given to the examination setters for marking; and records were communicated to the researcher. Thereafter, the test scripts and marking schemes were given to respective mathematics teachers for them to do corrections with the pupils.

\section{Mobile Phones}

Mobile phones were needed to facilitate communication with parents and teachers. Communication was necessary for inquiry and clarification of arising matters. Mobile phones were preferred than other means of communication like the internet given that they are fast and affordable.

\section{List of Perceived Best Practices for Use of Educational Technology}

The involved stakeholders in the experimental group received a list of best practices to guide the use of the developed technology. The aim was to make them informed of their roles regarding the use of the new technology. The control group was not provided with the list of best practices as it was treated under traditional practices and this differentiated it from the experiment group.

\section{Focus Group Meetings}

Meetings have been found to be effective tools of communication in terms of coordination and decision making (Garcia, Kunz and Fischer, 2003). In this investigation, the participants could present and share ideas, learn and discuss issues that facilitated the attainment of the intended goals and objectives of the project. The developed model of technology demanded participation of the key stakeholders for effective integration of the new technology. As in this case, two researcher-teachers' meetings were conducted; one for formative evaluation and another for summative evaluation of the experiment. The stakeholders were notified about date, time, place and objectives before the meetings took place.

\section{Procedures for the Experiment}

The designed experiment involved six steps as follows:

\section{Step 1: Selection of Classes for the Experiment}

The researcher was aware that the experiment could interfere with some school normal routines. For example, Standard Seven pupils were preparing for the Primary School Leaving Examination and therefore, involving them in the experiment could affect their preparations. With that in mind, Standard Six pupils were more convenient given their freedom from national examinations and their maturity as opposed to pupils in lower grades.

\section{Step 2: Partnership Contracting}

As part and parcel of the model, partnership contracting seeks for the stakeholder's commitment to perform their respective roles. This strategy was performed to the experimental group. The commitment of teachers was solicited through a meeting where the researcher explained about the model and the associated technology. Teachers were also requested and they agreed to champion the consequent strategies. The class teachers held training sessions to explain to their pupils about the experiment where pupils filled and signed a form to submit their willingness to adopt the model and the associated technology. The commitment of parents was sought in a parent-school meeting where head teachers and the researchers had an opportunity to explain about the model and the associated technology. The head teachers of the experimental group sent the contractual forms via the pupils for the parents to complete and sign. The contracts were attached with the best practices of technology use and the target stakeholders agreed and signed the same.

\section{Step 3: Acquisition of the Proposed Technology}

Through a series of meetings and consultations, the researcher trained and guided teachers of the experimental group to design and record the stipulated content in the DVD. The design of the DVD considered the pedagogical and content aspects as stipulated by the National Examinations Council of Tanzania. The technology design preferences were suggested by stakeholders as the deliverable in the first two strategies of the model. For example, it was suggested for the presentation to be proliferated with use of teaching aid, examples and learners' activities. The participation of teachers in the technology design was essential to solicit their commitments in championing its adoption.

\section{Step 4: Technology Deployment}

This strategy allowed the dissemination and use of the designed technology and home assignment booklets to pupils of both experimental and control groups. The technology deployment by the experimental group required the adherence to the stipulated best practices. As an example, teachers 
were supposed to warn their pupils about the adverse consequences of technology abuse and teach them how to use the technology. Pupils for instance, were required to prepare and adhere to a learning schedule and note down important points and difficult areas while using the technology. Among other things, parents or guardians were supposed to make a follow up and provide necessary assistance to enable their children to make effective use of the supplied technology.

\section{Step 5: Assessment}

The effectiveness of the new model was achieved on the basis of the impact on pupils' performance in mathematics as reflected in in-school progress tests. To that effect, pupils in both experimental and control groups took three monthly progress tests which were then correlated with the pre-test as a covariance on the basis of which the scores of the progress tests were adjusted. Since the model strategies entice pupils to make intensive use of the educational technology, it was assumed that pupils in the experimental group would have spent more time in learning mathematics and hence, improve their test grades. In this step, comparison of performance in mathematics was made between the experimental and control groups and across the three levels of supervisory supports.

\section{Step 6: Participant Evaluation}

The teachers, parents and learners of the experimental group were allowed to air out their views about the usefulness of the implemented model in enhancing the teaching and learning environments. The responses were analysed and presented in this paper as research findings.

\section{Validity and Reliability}

The validity of data was ensured by establishing early familiarity with the cultural environments of the participants before data collection dialogues. In the process, basic information about the participants was important before they could be approached for interview appointments. Apart from enabling the researcher to focus on pertinent issues in the course of actual interviews, a friendly environment was also cultivated such that respondents could freely supply the needed information (Lincoln, 1995; Erlandson, Harris and Allen, 1993). In addition, research instruments were developed and refined by research experts. The study deployed numerous data collection techniques such as experiment observation, questionnaire and focus group to enhance reliability of the research findings.

\section{Data Analysis}

The generated data were both quantitative and qualitative. Quantitative data was analysed through descriptive statistics, generating percentages and means. The General Linear Model (Analysis of covariance - ANCOVA) was applied to determine the performance of pupils in mathematics. The ANCOVA was intended to trade off variations in dependent variables by adjusting the mean value within conditions. To that end, the pre-test served as convariance.

The qualitative data was analysed through the inductive approach. Inductive data analysis employs detailed reading to derive concepts, themes or a model through interpretation (Creswell and Plano, 2007; Thomas, 2006). The use of this approach is supported by Bryman and Burgess (1994) and Dey (1993). Operationally, the researcher read and examined the data repeatedly, identifying key words and concepts for coding. The codes were rechecked, refined and combined in line with the research objectives. The analysis culminated in explanations, conclusions and recommendations.

\section{Ethical Considerations}

Before actual implementation of data collection, an introductory letter was obtained from the Meru District authority directing school administrators to allow the researcher access to schools. It was also important to brief the participants on the orientation and purpose of the study, protocols and benefits to the society. Participants were assured of confidentiality of supplied information and identities. To strengthen this, data were stored in files and computers which were passwordencrypted. Hard copies were kept in a secure place.

Informed consent was sought from participants to voluntarily and freely participate in the study. Research assistants were duly oriented to ethical issues and care was exercised to avoid any fabrication of data. Additionally, the participants had the right to access the final report. In order to ensure smooth communication, the research tools for pupils, parents and teachers were presented in Kiswahili language.

\section{Results and Discussion}

This section presents and discusses research findings on the basis of the results of the investigation. 
Research Question 1: Does Technology integration modelling for out-of-School Time Learning improve performance in Mathematics in Primary Schools?

This research question called for testing of the following null hypothesis: Technology integration modelling for out-of-School Time Learning does not improve performance in Mathematics in Primary Schools.

As shown in Table 1, the overall mean for the three tests was $29 \%$ for the experimental group. On the other hand, the mean for the control group was
22\%. This implies that the experimental group performed higher than the control group with respect to all OST levels of supervision. The mean score for high levels of supervision was $25 \%$ for the experimental group, against $19 \%$ recorded in the control group. As for the moderately supervision, the mean score was $30 \%$ for the experimental group versus $24 \%$ for the control group. Conversely, the mean score for low supervision was 33\% for the experimental group against $24 \%$ for the control group.

Table 1: GLM test for use of academic performance in work done in-school

\begin{tabular}{|c|c|c|c|c|c|c|c|c|c|}
\hline \multirow[t]{2}{*}{ GROUPS } & & & \multirow[t]{2}{*}{$\mathbf{N}$} & \multirow{2}{*}{$\begin{array}{l}\text { Mean } \\
\text { before data } \\
\text { transformation }\end{array}$} & \multicolumn{5}{|c|}{ After data transformation } \\
\hline & & & & & $\begin{array}{l}\text { Mean } \\
\text { (M) }\end{array}$ & $\begin{array}{l}\text { Degree } \\
\text { of } \\
\text { freedom } \\
\text { (f1) }\end{array}$ & $\begin{array}{l}\text { Degree } \\
\text { of } \\
\text { freedom } \\
\text { (f2) }\end{array}$ & $\begin{array}{l}\text { F-test } \\
\text { (F) }\end{array}$ & $\begin{array}{l}\text { P- } \\
\text { value } \\
\text { (P) }\end{array}$ \\
\hline \multirow{3}{*}{ Overall Groups } & & Experiment & 99 & 29 & 1.40 & 1 & 180 & 28.63 & 0.000 \\
\hline & & Control & 83 & 22 & 1.27 & & & & \\
\hline & & Sum & 182 & & & & & & \\
\hline \multirow{6}{*}{$\begin{array}{l}\text { Levels of OST } \\
\text { Supervisory } \\
\text { supports }\end{array}$} & 2.1 Highly & Experiment & 32 & 25 & 1.321 & 1 & 54 & 8.189 & 0.006 \\
\hline & supervised & Control & 24 & 19 & 1.195 & & & & \\
\hline & 2.2 & Experiment & 35 & 30 & 1.428 & 1 & 67 & 14.110 & 0.000 \\
\hline & Moderately & Control & 34 & 24 & 1.308 & & & & \\
\hline & supervised & Experiment & 32 & 33 & 1.472 & 1 & 55 & 11.450 & 0.001 \\
\hline & & Control & 25 & 24 & 1.297 & & & & \\
\hline
\end{tabular}

The General Linear Model (GLM) with repeated measures suggested a statistically significant difference in mean scores between the experimental group and control group at 95\% confidence level whereby, $F(1,180)=28.63, p=0$ as the overall test, and $F(1,54)=8.189, p=0.006$ for high supervision. As for moderate and low supervision, the scores were $F(1,67)=14.110, p=$ 0 ; and $F(1,55)=11.450, p=0.001$ respectively. Thus, the null hypothesis was rejected at $95 \%$ confidence level, suggesting that the use of the proposed model of technology integration for OST learning significantly improves performance in mathematics among primary school pupils.

Generally, the findings show that OST learning technology enhances pupils' performance in mathematics. This corroborates early studies which also revealed a positive correlation between the use of OST technology and academic performance among primary school pupils. Letao \& Kelly (2010) examined whether 15-years old pupils using computer frequently achieved better than those who did not frequently use technologies. The study found that the performance of those pupils who used computers daily was significantly higher than those who used the computers less frequently. Similarly, the findings agree with the results of a study by Borzekowski (2018) which tested the effectiveness of Ubongo Kids program in improving the academic performance in Tanzania. The study indicates that the use of educational technology by OST learners in primary schools leads to significant improvement in the performance of mathematics. Studies have further supported that strategies that encourage OST learning are linked with reduced drop-out, early pregnancy rates, avoidance of risky practices and consequently improved academic performance (Huang et al., 2000; McLaughlin, 2000; Clark, 1988; Hamilton and Klein, 1998).

Research Question 2: What are the perceptions of primary school teachers, parents and learners on the usefulness of technology integration modelling in improving the environments for teaching and learning of mathematics in OST?" 
This research question presents findings on the opinions of the involved stakeholders in relation to the usefulness of technology integration modelling in improving the environment for teaching and learning of mathematics in primary schools. The results involved both formative and summative evaluation where the former and the latter were conducted during and after experiment respectively.

\section{Opinions during the Experiment}

Focus group meetings were used to seek opinions from head teachers and subject teachers. In total, eight respondents attended the meetings whereby five were mathematics teachers and three were head teachers in the schools constituting the experimental group. The aim was to locate areas which could be improved, including renewal of commitments of the stakeholders. The meetings were also meant to remind participants of their roles in intended mission. The findings revealed that all participants acknowledged that the model and the associated technology enhanced instructional processes and the academic achievement.

For instance, it was reported that the strategies involved in developing the model were instrumental in improving relationship between schools and parents as justified by increased contacts through telephones and letters. In particular, 4(50\%) of the respondents had received acknowledgement from parents in honour of the materials availed to their children. One (12.5\%) teacher revealed that one of the parents had bought a flash disk in which he copied the DVD content for back up. Two teachers (25\%) unveiled that some parents had set aside time for their children to watch the DVD content. One of the parents was recorded saying that as the child watched the DVD presentation, the rest of the children were asked to leave the sitting room to make the child more attentive. In the same veins, one $(12.5 \%)$ teacher said that one parent reported to have spent at least an hour daily going through the DVD presentation with the child.

Furthermore, all teachers acknowledged that the strategies adopted in developing the model made the learners more active, self-confident and interested in learning of mathematics. The teachers reported further that pupils were more attentive, disciplined and busy with note-taking in mathematics classes. Additionally, one (12.5\%) teacher observed that since DVDs were associated with teaching aids, pupils could make their own learning aids and bring them to class. All teachers further explained that the use of the developed educational technology and the associated strategies facilitated timely coverage of the subject content while easing understanding of concepts. One $(12.5 \%)$ of the subject teachers confirmed that concepts which seemed difficult to grasp were easier with the use of OST learning technology.

The findings further showed that all Mathematics teachers continuously encouraged parents and pupils to collaborate to ensure actual use of OST educational technology while two (25\%) of them reported that some parents had requested replacement of scratched DVDs. However, there was an instance reported by one (12.5\%) of the teachers that a parents had complained that his child once attempted to view a music program instead of concentration on the DVD content. The participants thus, insisted that pupils should be closely monitored to ensure that they do not abuse the use of educational technology. In general, pupils and parents were in support of the proposed model and the accompanied technology. More importantly, all teachers expressed their commitment to keep championing the new technology in partnership with learners and parents.

\section{Post Experiment Stakeholders' Opinions}

The opinions sought after the experiments were intended to appraise the usefulness of the proposed model for integration of OST technology and the accompanied educational technology. The opinions were sought from parents and pupils using structured questionnaires. To mathematics teachers and head teachers, unstructured interviews were adopted.

\section{Post Experiment Parents' Opinions}

Parents were asked to give opinions on how the use of the proposed model had cultivated interest in mathematics among children. The results are presented in Table two.

Table 2: Influence of the Proposed Model

\begin{tabular}{lcc}
\hline \multicolumn{1}{c}{ Answer } & Frequency & Percent \\
\hline Disagree & 2 & 2 \\
Neutral & 2 & 2 \\
Agree & 55 & 46 \\
Strongly agree & 60 & 50 \\
Total & $\mathbf{1 1 9}$ & $\mathbf{1 0 0}$ \\
\hline
\end{tabular}

With reference to Table 2, most parents showed that the use of the proposed OST technology enhanced interests in mathematics among primary school children. This is justified by $50 \%$ and $46 \%$ of 
the parents who supported or strongly supported the view, respectively.

\section{Post experiment Teachers' Opinions}

The subject teachers and head teachers also gave their opinions after the experiment. The opinions specifically pertained to the usefulness of the model for OST technology integration for pupils.

As regards the usefulness of the designed OST technology integration for learners, the mathematics teachers and head teachers were motivated to see how the model could impact pupils' interest in mathematics. As explained in the focus group meetings, subject teachers indicated that pupils demonstrated continual interest in mathematics as evidenced by increased attention and participation in class activities. Findings also showed that three $(37.5 \%)$ of the mathematics teachers had observed increased pupils' selfconfidence and independent mind in attempting class assignments. Additionally, two (25\%) of the teachers had noted increased competition among pupils as they asked and answered questions, presumably because of increased interest and selfconfidence. This had in turn enhanced performance in the subject as reported by six (75\%) of the teachers.

As for the usefulness of the model for teachers, it was reported that the proposed model and the related technology had eased their teaching. For example, four (50\%) of the teachers said that the intervention had improved their curiosity and creativity in developing and applying new teaching materials and techniques. This was particularly due to their participation in designing the educational technology which had significantly changed their mind set as regards improvisation of instructional materials. As noted in the previous presentation, pupils had developed similar skills. It is thus suggested that teachers and pupils should be continuously involved in designing locally available instructional materials.

As reported in the focus group meetings, the intervention also enabled timely coverage of the subject content as reported by $25 \%$ of mathematics teachers. While the researcher had observed earlier that mathematics teachers complained that it was difficult to cover the syllabus because it involved a lot of content, it could be concluded then that the proposed model is valuable in addressing the challenge. Two (25\%) of the mathematics teachers explained further that strategies incorporated in the proposed model had increased their interest in teaching while also enhancing pupils' competence in mathematics.

\section{Future Strategies by Teachers}

The involved mathematics teachers demonstrated their future commitment to the use of the designed technology and perceived best practices. This was partly justified by four (50\%) of the teachers who expressed willingness to keep working closely with parents, encouraging them to ensure that pupils effectively use OST learning technology. Further evidence comes from one (12.5\%) of the head teachers' insistence on more meetings between parents and schools to discuss issues related to the use of the perceived best practices and technology for the good of pupils. Moreover, six (75\%) of the teachers promised to keep issuing more home assignments to pupils, with one $(12.5 \%)$ indicating willingness to adopt educational technology in teaching and encouraging pupils to use technology during the OST. One (12.5\%) mathematics teacher showed interest in initiating a mathematics club in the neighbouring schools to engage pupils in OST during weekend and long leaves. What is encouraging is that four (50\%) of the teachers explained that they would keep encouraging pupils to adhere to the perceived best practices they adopted during the study to make the practices sustainable. The findings are an indication that the teachers and head teachers were convinced to adopt and champion the use of educational technologies to improve learning.

\section{Post Experience Learners' Opinions}

After the experiment, learners were consulted to appraise the strategies incorporated in the model in terms of accelerating the use of the educational technology to which they were exposed. The findings are summarized in Table three.

\begin{tabular}{lcc}
\multicolumn{3}{c}{ Table 3: Learners' Evaluation } \\
\hline Answer & $\mathbf{f}$ & Percent \\
\hline Strongly disagree & 0 & 0 \\
Disagree & 4 & 3 \\
Neutral & 0 & 0 \\
Agree & 64 & 47 \\
Strongly agree & 67 & 50 \\
Total & $\mathbf{1 3 5}$ & $\mathbf{1 0 0}$ \\
\hline
\end{tabular}

As depicted in Table 3, it is revealed that $50 \%$ of the pupils strongly agreed and $47 \%$ agreed that the proposed model had accelerated the use of educational technology. Only the minority $3 \%$ of 
them showed that the model did not accelerate the use of educational technology. It could thus be concluded that the proposed model is useful in hastening integration of educational technology.

Pupils were also required to rate the extent to which the use of the model improved the parents' supervision as reflected in table 4 whereby $47 \%$ of the pupils strongly agreed and $47 \%$ agreed that the model had improved parents' supervision and support. However, $5 \%$ disagreed and 1\% strongly disagreed that the model had improved parents' supervision and support. Since majority of the pupils either strongly agreed or agreed, it is concluded that the model had improved parents' supervision and support.

Table 4: Improvement of Parental Supervision

\begin{tabular}{lcc}
\hline \multicolumn{1}{c}{ Answer } & f & Percent \\
\hline Strongly disagree & 1 & 1 \\
Disagree & 7 & 5 \\
Agree & 65 & 47 \\
Strongly agree & 65 & 47 \\
Total & $\mathbf{1 3 8}$ & $\mathbf{1 0 0}$ \\
\hline
\end{tabular}

The usefulness of technology integration modelling in enhancing the teaching and learning environments is also manifested in the existing literature. Ashleigh (2010) and David (2013) ascertain that the learning process that is well guided by best practices tends to develop in children the spirit of independent learning and interest in learning activities. A study by Tabassum and Hanan (2016) revealed that the positive use of technology is positively associated with pupils' active and self-directed learning. It is also argued that participation of learners in positive use of technology in OST learning improves their interpersonal skills and aspirations for higher learning (Schinke, 1999; U.S Department of Education, 1998; Posner \& Vandell, 1999). It is further reported that the strategies to guide learners to participate in learning activities during OST results in reduced drop-out rates, early pregnancy and avoidance of risky behaviors (Huang et al., 2000; McLaughlin, 2000; Clark, 1988; Hamilton and Klein, 1998).

\section{Conclusions and Recommendations Conclusions}

With respect to whether technology integration modelling impact on the performance of mathematics in primary school, the study concludes that technology integration modelling for Out-OfSchool Time in primary schools is attributed to significant improvements in the performance in Mathematics. Regarding the perceptions of teachers, parents and pupils on the usefulness of technology integration modelling in enhancing the teaching and learning environments, it is concluded that technology integration modelling not only enticed teachers, parents and pupils to collaboratively allow more time and commitments in favour of Mathematics subject but also encouraged learners to build interest, confidence and creativity in the subject.

\section{Recommendations}

On the basis of the conclusions made in this study, teachers are encouraged to cooperate with school administration to integrate technology in their teaching activities in order to inculcate into pupils the attitude of learning through technology. Parents are also advised to assist their children by providing technology resources and dedicate time to supervise their children for effective OST learning. Pupils should respond to their teachers and parents' initiatives by setting time for OST learning and do so through the available technology so as to improve their academic performance particularly in mathematics. The Tanzanian Government and other educational stakeholders should device and reinforce implementation of standards, procedures and practices that are best to direct the positive use of educational technology in primary schools and particularly in OST. The Government is also advised to initiate and support the awareness campaigns that inspire teachers, parents and pupils to embrace the use of technology in the teaching and learning activities particularly in OST learning. This will eventually address the challenges that confront the advancement of educational sector such as the shortage of learning materials and ultimately contribute to the improvements in academic performance in primary schools. Further studies can be conducted to find out how technology integration modelling for OST learning can be integrated with in-school learning for optimal application of educational technology and further improvement in academic performance.

\section{References}

Adomi, E. and Kpangban, E.(2010). Application of ICT in Nigerian secondary schools, Delta State University, Asaba. 
Amon Mbelle et al. (2003). School enrolment, performance and access to education in Tanzania. University of Dar es Salaam. Retrieved from http://www.repoa.or.tz/d ocuments_storage/Publications/Reports/03. 1-_Mbelle_Katabaro.pdf.

Ashleigh C. (2010). Incorporating technology in outof-school time programs: Benefits, challenges and strategies. Retrieved from http://www.childtrends.org/wp-content/u ploads/2010/03/Child_Trends2010_03_01_ R B_TechnologyOST.pdf.

Bryman, A. \& Burgess, G. (1994). Analyzing qualitative data. London: Routledge.

Centre For Public Education (2016). Educational equity. Retrieved from https://www.c enterforpubliceducation.org/educationaleq uity.

Borzekowski, D. L. (2018). A quasi-experiment examining the impact of educational cartoon on Children Jouinal of applied developmental psychology, 54, 53-59.

Communication Initiative Network (2014). Ubongo Kids Cartoon Series. Retrieved from https://www.comminit.com/africa.

Clark, R. (1988). Critical Factors in why disadvantaged children succeed or fail in school. New York: Academy for educational development.

Collins, A. (1991). The role of Computer Technology in Restructuring Schools. Phi Delta Kappan, 73(2), 28-36.

Creswell, J., \& Plano, L. (2007). Designing and conducting mixed methods research. London, Sage Publications.

Center for Education Innovations (n.d ). ELIMU Community Light: Early childhood development program. Retrieved from http://www.educationinnovations.org/prog ram/elimu-community-light-early-childho od-development program\#stha sh.du 7giivx. dpuf.

Clark, R. (1988). Critical Factors in Why Disadvantaged Children Succeed or Fail in School, Academy for Educational Development, New York.
Chalk Board Project (2008). A review of research on extended research learning timein $\mathrm{K}-12$ schools. Retrieved from http://chalk board pro ject.org/image s/PDF/Extended\%2 OLearnin g\%20final\%20rev.pdf.

David, A. (2013). iPads in the classroom: embedding technology in the primary curriculum. Retrieved from http://www.thegu ardian .com/teacher-network/teacher-blog/2013/ mar /06/ipad-I pod-technology-primarycurriculum.

Dey, I. (1993). Qualitative data analysis: A userfriendly guide for social scientists. London, Routledge.

Erlandson. In D. A., Harris, E., L \& Allen, S. D. (1993). Doing naturalistic inquiry: a guide to methods. London: Sage.

Georgia, H. et al. (2004). Using Technology to Support Academic Attainment for At-Risk Teens During Out-of-school Time. Retrieved from https://www .ncjrs.gov /App/public cations/abstract.aspx?id=234855.

Garcia, A. C. B., Kunz, J., \& Fischer, M. (2003, August). Meeting Details: Methods to instrument meetings and use agenda voting to make them more effective. In meeting of the Center for Integrated Facility Engineering, Stanford.

Huang, D. et al (2000). A Decade of Results: The Impact of LA's BEST Afterschool Enrichment Initiative on Subsequent Student 20 Achievement and Performance. University of California, California .

Hultman, J. (2004). Technology Adoption and embeddedness". Retrieved from www.impgroup.org/uploads/papers/4560.p df.

Hamilton J. (2007). Logic Models in Out-of-school TimePrograms: What are they and why are they important? Washington DC.

Hamilton, L.S., \& Klein, S.P. (1998). Achievement test score gains among participants in the Foundation's school-age enrichment program. Santa Monica, CA: Rand Corporation.

Harvard Family Research Project (HFRP) (1999). A Summary of formal evaluations of afterschool programs' impact on behavior, 
safety and family life. Retrieved from http://www.gse.harvard.edu/hfrp/projects/ afterschool/mott/ pleep.html.

Indianapolis Afterschool Coalition (2002). After school programs: Basic standards. Retrieved from https://www.afterschoolcoalition.org.

Ippmedia (October 19, 2014), Nokia MobileMathematics: A solution for mathematic failure in Tanzania? http://www.ippm edia.co $\mathrm{m} /$ frontend/?l=73323.

IIEP. (2010). In search of quality, what the data tell us. Retrieved from https://www.iiep.unesc o.org/en/search-quality-what-data-tell-us2723.

Jonassen, D., Peck, K., \& Wilson, B. (1999). Learning with technology: A constructivist perspective, Upper Saddle River: NJ: Prentice Hall.

Juniu, S. (2006). Use of technology for constructivist learning in a performance assessment class. Measurement in Physical Education and Exercise Science, 10(1), 67-78.

Kellogg Foundation (2000). Logic Model Development Guide, Battle Creek.

Kelly, A. (2013). Technology can empower children in developing countries - if it's done right. USA: Atlantic University.

Kiwango, T. A. (2018). A model to hasten technology integration for out-of-school time primary school learning. Doctor of philosophy in computer science. The University of Dodoma, Tanzania.

Kalhotra, S. K. (2013). A Study of Causes of Failure in Mathematics at High School Stage. Academic Research International, 4(5).

Letao S, Kelly D (2010). School Computer Use and Academic Performance. University of Kentucky, USA.

Lincoln, Y. S. (1995). Emerging criteria for quality in qualitative and interpretive research. Qualitative Inquiry, 1(2), 275-289.

Lamudi, A. (2015). Which Areas Have the Best Internet Connection In Tanzania? Retrieved fromhttps://www.lamudi.co.tz/journal/ which- areas-have-the-best-internetconnection-in Tanzania.

Malmberg, L., \& Sumra, S. (2001). Socio-cultural factors and Tanzanian primary school students' achievements and school experience. Utafiti, 4(2), 207-219.

Mark, B. (2003). Adverse effects of private Supplementary Tutoring Dimensions, Implications and Government Responses. Paris: International Institute for Educational Planning.

McLaughlin, M. (2000). Community Counts: How Youth Organizations Matter for Youth Development, Public Education Network, Washington, DC.

Metlife foundation. (2011). Aligning afterschool with the regular school day: The perfect complement. Retrieved from https:/ /www.afterschoolalliance.org/issue_briefs/l ssue_schoolDay_50.pdf.

Miller, B. (1995). Out-of-school time: Effects on learning in the primary grades. School-age child care project. National Institute on Out of School Time, USA: Wellesley College.

Maddux, C. (2001). Educational Computing: Learning with Tomorrow's Technologies (3rd Edition), Pearson, UK.

McKenzie, W. (2000). "Are you a technoconstructivist?". Retrieved from[ht tp:// www.educationworld.com/a_tech/tec h/tec h005.shtml].

Mazana, M.Y et al. (2020). Assessing students' performance in mathematics in Tanzania: the teacher's perspective. International Electronic Journal of Mathematics Education, 15(3), em0589.

Njiku, J. (2019). Mathematics Performance across Gender and Who Owns a School. Huria: Journal of the Open University of Tanzania, 26(1), 141-150

Posner, J. K., \& Vandell, D. L. (1999). After school activities and the development of lowincome urban children: A Longitudinal study. Developmental Psychology, USA

Schinke, S. (1999). Evaluation of Boys and Girls Club of America's educational enhancement program (unpublished manuscript).

Rakes, G. C., Flowers, B F., Casey, H. B.(1999). An analysis of instructional technology use and constructivist behaviours in $\mathrm{k}-12$ teachers. International Journal of Educational Technology, 1(2), 1-18. 
Rob, V. (1996). Educational indicators: what's to be measured? Retrieved from https://ser vice s.ia db.org/wm sfiles/products/Pub lications/2218419.pdf.

Sarah K. et al(2012), Developing an Agile and Responsive Curriculum to Meet the Diverse Needs of Students and Employers in the 21st Century. Retrieved from https://www.jisc.ac.uk/guides.

Swart P. and Wachira E. (2010). Tanzania: ICT in Education situational Analysis. Retrieved from http://www.gesci.org/assets/fi les/K nowl edge\%20Centre/Situational\%20An alysis_Tanzania.pdf.

Sigalla, N. (2013). Investigation of factors hindering quality education in secondary schools in Mbeya, Tanzania. International Journal Learning and Development, 3(3), 3-5.

Sumra, S., \& Katabaro, J. (2014). Declining Quality of Education: Suggestions for Arresting the trend. Retrieved from https://www.thdr.o r.tz/docs/thdr-dp-63.pdf.

TCRA (2013). Assessment Report on Migration from Analogue to Digital Broadcasting and Analogue Switch-off Processes in Tanzania. Retrieved from http://www.tcra.g o.tz/index.php/publication-and-statistic s/re ports.
Thomas, D. (2006). University of Auckland, School of population health, private bag 92019, Auckland. American Journal of Evaluation,10(2), 5-9.

Tabassum R. and Hanan M. (2016). Technology Use, Self-directed Learning, Student Engagement and Academic Performance: Examining the interrelations, Computers in Human Behavior, Volume 63, October 2016, Pages 604-612.

Terzian, M., et al. (2009). Why teens are not involved in out-of-school programs, the youth perspectives. Retrieved from https://www.childtrends.org/wp-con ten t/upl oads/2013/04/6.pdf.

UNESCO (2014). UNESCO Education Strategy. Retrieved from https://unesdoc.unesco.org /images/0023/002312/231288e.pdf.

URT (1998). Private tuition in Primary and Secondary Schools. Dar es Salaam: Ministry of Education and Culture

U.S. Department of Education. (1998). Monitoring school quality: An indicators Report. Retrieved from httpss://nces.ed.gov/pub s2001/2001030.pdf.

Watson, S. (2000). Using results to improve the lives of children and families: A guide for publicprivate child care partnerships. Retrieved from https://files.eric.ed.gov/fu Iltext/E D4498. 